\title{
UPAYA MENINGKATKAN MINAT BELAJAR SISWA PADA POKOK BAHASAN PENYETARAAN PERSAMAAN REAKSI KIMIA SEDERHANA MELALUI METODE TELUNJUK KANAN DAN TELUNJUK KIRI DI KELAS X-D MAN 3 BANJARMASIN TAHUN 2014/2015
}

\author{
Chairunnisa \\ MAN 3 Banjarmasin, Kimia \\ Email: nisa63ch@gmail.com
}

\begin{abstract}
This class action research uses the right index method and the left index finger. The results showed that in cycle 1 the ability of teachers to apply the right and left index finger method on the subject of equalization of simple reaction equations is good and there is increasing understanding of students. Learning completeness in the first cycle classically reached $70.75 \%$, while the second cycle reached $97.20 \%$. In addition, there is an increase in cooperative skills, especially the ability of students to perform social relationships such as want to ask others, respect the opinions of others, willing to accept the advice of others and want to contribute knowledge, which before the action is less able and after the action becomes very capable.
\end{abstract}

Key Word: Interest in learning, the method of two right index finger and left index, simple chemical reaction equation

\begin{abstract}
ABSTRAK
Penelitan tindakan kelas ini menggunakan metode telunjuk kanan dan telunjuk kiri. Hasil penelitian menunjukan bahwa pada siklus 1 kemampuan guru menerapkan metode telunjuk kanan dan telunjuk kiri pada pokok bahasan penyetaraan persamaan reaksi sederhana adalah baik dan ada peningkatan pemahaman siswa. Ketuntasan belajar pada siklus I secara klasikal mencapai 70,75 \%, sedangkan siklus II mencapai 97,20 \% . Selain itu, terdapat peningkatan keterampilan kooperatif terutama kemampuan siswa untuk melakukan hubungan sosial seperti mau bertanya pada orang lain, menghargai pendapat orang lain, mau menerima saran orang lain dan mau menyumbangkan ilmu, yang sebelum tindakan kurang mampu dan setelah dilakukan tindakan menjadi sangat mampu.
\end{abstract}

Kata kunci : Minat belajar, metode dua telunjuk kanan dan telunjuk kiri, persamaan reaksi kimia sederhana

\section{PENDAHULUAN}

Pendidikan berbasis kompetensi adalah pendidikan yang menekankan pada kemampuan yang harus dimiliki oleh lulusan suatu jenjang pendidikan. Kompetensi lulusan suatu jenjang pendidikan, sesuai dengan tujuan pendidikan nasional, mencakup komponen pengetahuan, keterampilan, kecakapan, kemandirian, kreativitas, kesehatan, akhlak, ketaqwaan (Ditjen Dikdasmen, 2003 : 1).

Mata pelajaran kimia bagi siswa kelas X SMA merupakan mata pelajaran baru. Mereka harus dapat beradaptasi terhadap karakter mata pelajaran kimia. Disamping dapat berhitung dengan angka-angka, siswa juga dituntut dapat memahami konsep dan aplikasinya. Oleh karena itu, agar kompentensi dasar ilmu kimia dapat tercapai maka sangat diperlukan kreativitas untuk dapat memotivasi siswa agar cinta ilmu kimia. Mata pelajaran kimia harus merupakan mata pelajaran yang sangat ditunggu kehadirannya.

Standar kompetensi kedua mata pelajaran kimia kelas $\mathrm{X}$ semester 1 berbunyi : "Mendiskripsikan hukum- 
hukum dasar kimia dan penerapannya dalam perhitungan kimia (stoikiometri). Standar kompentensi ini harus dicapai setelah siswa memiliki kompentensi mendiskripsikan struktur atom, sifat-sifat periodik unsur dan ikatan kimia serta struktur molekul dan sifat-sifatnya. Dengan kata lain sebelum memasuki standar kompetensi ke-2 siswa telah mengenal nama unsur dan ikatan kimia antar unsur dan antar molekul, serta dapat menentukan rumus kimia sederhana dari 2 atau 3 unsur yang berikatan.

Salah satu kompetensi dasar dalam standar kompetensi kedua adalah menuliskan nama senyawa anorganik dan organik sederhana serta persamaan reaksinya. Kompetensi dasar ini merupakan kompetensi pokok dan mendasar yang harus sangat dikuasai siswa. Konsep-konsep materi dalam kompensi ini merupakan modal utama siswa dapat mencapai standar kompentensi tersebut. Standar kompetensi ini merupakan dasar bagi standar kompetensi selanjutnya.

Berdasarkan pengalaman dan diskusi dengan para pengajar ilmu kimia di MAN 3 Banjarmasin, pada umumnya siswa mengalami kesulitan dalam menyetarakan persamaan reaksi. Hal ini disebabkan para siswa belum mengetahui nama-nama dan lambang-lambang dari berbagai unsur dengan baik, belum paham maksud reaksi setara, belum tahu akan fungsi dari koefisien reaksi, bagaimana langlah menyelesaikan persamaan reaksi yang benar, serta masih ada yang salah dalam operasi matematika sederhana.

Operasi matematika semakin rumit apabila dalam persamaan reaksi melibatkan semakin banyak unsur. Hal ini dapat menimbulkan kejenuhan dan berkesan menyulitkan bagi siswa. Berdasarkan latar belakang masalah di atas maka dapat dirumuskan masalah sebagai berikut : bagaimana meningkatkan kemampuan siswa kelas $\mathrm{X}$-D dalam menyelesaikan penyetaraan persamaan reaksi kimia sederhana dengan menggunakan metode telunjuk kanan dan kiri? Bagaimana minat siswa terhadap pembelajaran penyetaran persamaan reaksi dengan menggunakan metode telunjuk kanan dan kiri?

Berdasarkan masalah di atas, maka penelitian tindakan ini bertujuan untuk meningkatkan pemahaman siswa terhadap materi penyetaraan persamaan reaksi kimia sederhana menggunakan metode telunjuk kanan dan telunjuk kiri. Dan meningkatkan minat belajar siswa kelas X-D MAN 3 Banjarmasin terhadap metode telunjuk kanan dan telunjuk kiri.

\section{METODE PENELITIAN}

Rencana tindakan ini dilaksanakan dengan menggunakan rancangan penelitian tindakan kelas (classroom action research). Siklus I dilaksanakan dalam satu kali tindakan kelas dan siklus II dilaksanakan dalam sekali tindakkan kelas, sehingga untuk 2 siklus terdapat dua kali tindakan kelas. Pembelajaran siklus II hanya difokuskan pada konsep yang belum dikuasai oleh siswa saja, yang ditemukan dari hasil evaluasi pada siklus I. Tiap siklus terdiri dari tahapan-tahapan; (1) perencanaan (planning), (2) pelaksanaan tindakan (action), (3) observasi dan evaluasi, serta (4) analisis dan refleksi. Evaluasi dilakukan setelah siklus I dan siklus II selesai.

Subyek penelitian adalah siswa kelas X-D MAN 3 Banjarmasin yang terdiri dari 38 siswa. Instrumen penelitian ini meliputi (1) media belajar penyetaraan persamaan reaksi kimia sederhana yang dikembangkan oleh peneliti (2) tes hasil belajar untuk mengukur tingkat pemahaman siswa (3) lembar observasi proses pembelajaran dan (4) angket respon siswa terhadap.

Hasil penelitian dianalisis secara deskriptif kualitatif untuk melihat peningkatan proses pembelajaran dan pemahaman siswa dan minat siswa terhadap materi penyetaraan persamaan 
reaksi kimia sederhana yang diajarkan dengan metode telunjuk kanan dan telunjuk kiri. Tindakan kelas dikatakan berhasil jika siswa yang tidak terindikasi mengalami peningkatan pemahaman mencapai tingkat penguasaan $\geq 70 \%$ sebanyak $\geq 85 \%$.

\section{HASIL DAN PEMBAHASAN}

Hasil observasi pada siklus I menunjukkan bahwa pada umumnya siswa masih beradaptasi dengan penggunaan metode telunjuk kanan dan telunjuk kiri. Namun demikian siswa tampak sangat antusias mengikuti pelajaran. Secara umum proses pembelajaran baik pada siklus I maupun II, berlangsung sangat baik dengan skor observasi kelas mencapai 95-100\%. Hasil pretes menunjukkan bahwa skor rata-rata siswa mencapai $25,10 \%$. Namun skor ini belum mencerminkan tingkat penguasaan siswa, karena siswa tidak bisa memberikan alasan mengapa memilih pilihan jawaban tertentu. Data tingkat penguasaan siswa tentang belajar penyetaraan persamaan reaksi kimia sederhana pada siklus I dan II disajikan pada pada Tabel 1.

Tabel 1. Tingkat Penguasaan Siswa Terhadap Materi Penyetaraan Persamaan Reaksi Kimia Pada Siklus I dan II

\begin{tabular}{|c|c|c|c|}
\hline \multirow[t]{2}{*}{ No. } & \multirow[t]{2}{*}{ Indikator } & \multicolumn{2}{|c|}{$\begin{array}{c}\text { Distribusi } \\
\text { Jawaban Benar }(\%)\end{array}$} \\
\hline & & Siklus I & Siklus II \\
\hline 1. & $\begin{array}{l}\text { Menyetarakan } \\
\text { persamaan } \\
\text { reaksi dengan } \\
2 \text { unsur }\end{array}$ & 88.5 & 99,5 \\
\hline 2. & $\begin{array}{l}\text { Menyetarakan } \\
\text { persamaan } \\
\text { reaksi } \\
\text { sederhaha } \\
\text { dengan lebih } \\
\text { dari } 2 \text { unsur } \\
\end{array}$ & 84,5 & 99,5 \\
\hline 3. & $\begin{array}{l}\text { Menyetarakan } \\
\text { persamaan } \\
\text { reaksi dengan } \\
2 \text { unsur dari } \\
\text { nama partikel } \\
\text { senyawanya }\end{array}$ & 60 & 96,5 \\
\hline 4. & Menyetarakan & 50 & 93,3 \\
\hline
\end{tabular}

\begin{tabular}{ll}
\hline \multicolumn{2}{l}{ persamaan } \\
reaksi \\
sederhana \\
dengan lebih \\
dari 2 unsur \\
dari nama \\
partikel \\
senyawanya \\
Rata-rata \\
kemampuan siswa \\
menjawab soal & \multicolumn{1}{c}{70,75} \\
\hline Keterangan : & \\
$\geq 95 \%$ & Istimewa \\
$80 \%-94,9 \%$ & Amat Baik \\
$65 \%-79,9 \%$ & Baik \\
$55 \%-64,9 \%$ & Cukup \\
$40,1 \%-54,9 \%$ & Kurang \\
$\leq 40 \%$ & Amat Kurang \\
\hline
\end{tabular}

Dari hasil tes awal diketahui tingkat pemahaman siswa terhadap penyetaraan persamaan reaksi kimia rendah walaupun sebelumnya telah dilakukan pemberian tugas membaca. Hasil ini dapat sebagai tolok ukur untuk mengukur kemampuan siswa sebelum mendapatkan pengajaran melalui pendekatan yang akan diberikan melalui tindakan-tindakan yang terdapat dalam siklus I dan siklus II.

Dari jumlah siswa kelas X-D yang berjumlah 38 siswa, sebanyak 6 orang siswa belum mencapai ketuntasan atau dengan kriteria kurang dengan nilai $<65$. Sebanyak 32 orang siswa sudah tuntas, walaupun dengan catatan sebanyak 7 orang memiliki nilai tepat 65 atau sama dengan cukup, sehingga presentase siswa yang telah mencapai ketuntasan belajar setelah dilaksanakan pembelajaran dengan metode TGT adalah : 27/38 x $100 \%=71,05 \%$ dengan catatan sebanyak $7 \quad(20,51 \%)$ siswa hanya memiliki nilai minimum ketuntasan yaitu 65 dan siswa yang belum berhasil mencapai ketuntasan belajar setelah dilaksanakan siklus I sebanyak : 6/35 x $100 \%=15,38 \%$

Melihat hasil yang diperoleh pada siklus I, pembelajaran penyetaraan 
persamaan reaksi kimia dengan menerapkan metode telunjuk kanan dan telunjuk kiri dapat dikatakan berhasil meningkatkan presentase ketuntasan belajar secara klasikal jika dibandingkan dengan pembelajaran oleh metode guru lain (persamaan matematika). Pada pembelajaran penyetaraan persamaan reaksi kimia adalah lebih baik. Guru mampu mengelola pembelajaran dan alokasi waktu yang sesuai dengan metode diskusi informasi dalam kelompok. Dalam hal ini kuis berupa pertanyaan diberikan setelah guru memberikan penjelasan ulang tentang konsep yang paling sedikit dipahami siswa. Siklus II dilaksanakan selama 1 kali penyajian kelas. Guru juga memberikan penugasan berupa pemberian soal-soal untuk dikerjakan dirumah oleh semua siswa. Siswa yang belum tuntas akan tertantang untuk

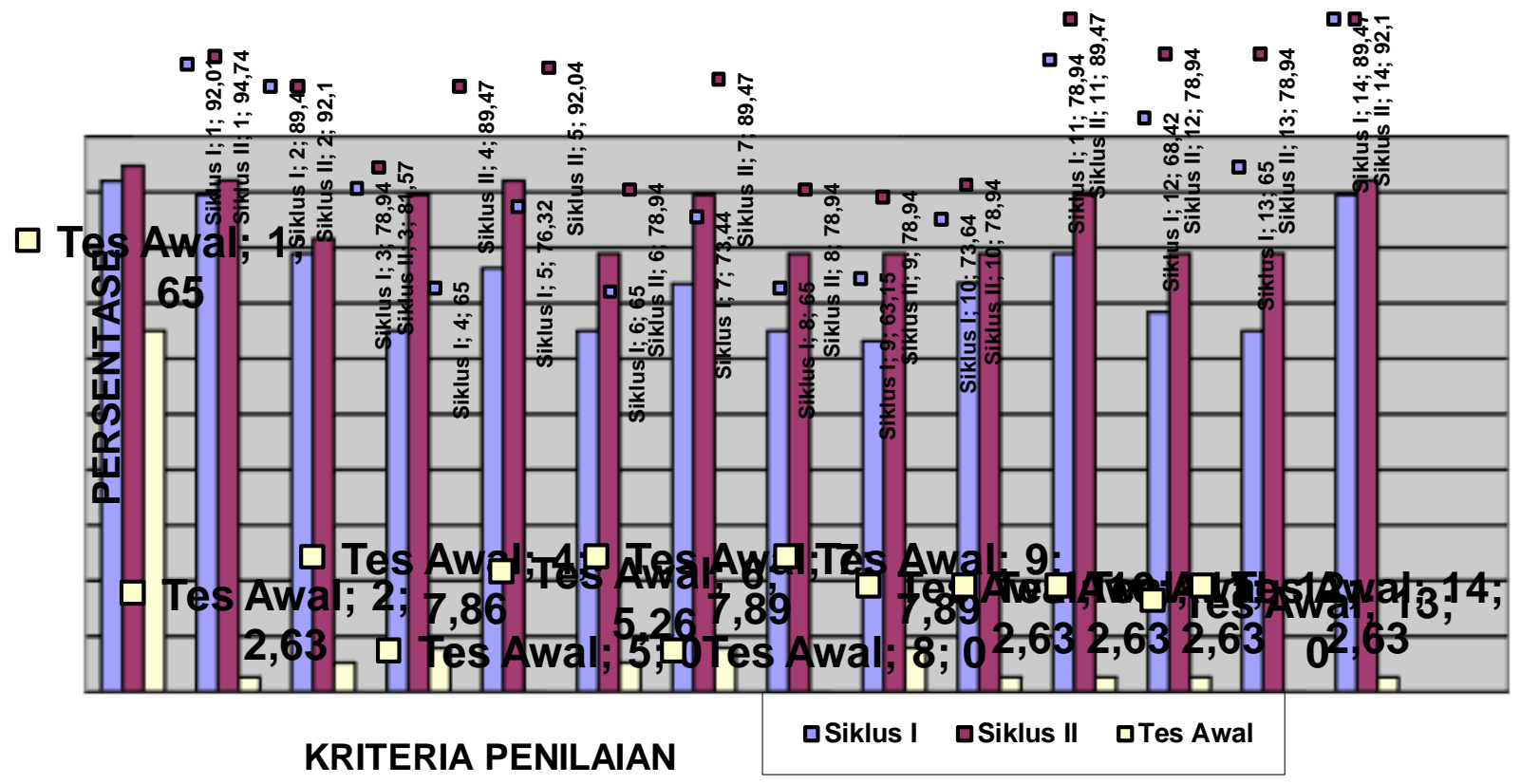

\section{Gambar 1. Tingkat penguasaan siswa terhadap konsep striktir atom dan ikatan kimia}

membuat siswa lebih antusias dalam mengikuti pembelajaran dan dapat menciptakan spontanitas belajar. Namun dari berbagai sisi masih terdapat kekurangan-kekurangan seperti pada penguasaan materi tata nama dan atom yang lebih dari pada dua unsur. Dari Kegiatan belajar mengajar (KBM) yang lain adalah pemanfaatan waktu yang tersedia belum optimal dilaksanakan.

Berdasarkan hasil refleksi tersebut di atas, pada siklus II dilakukan perbaikan pemahaman terhadap konsep yang masih belum dipahami. Penyajian kelas pada siklus II dilakukan dengan pemberian penjelasan oleh guru dengan belajar siklus II untuk mengoptimalkan waktu yang tersedia. Setelah siklus II, tingkat penguasaan berkisar antara cukup hingga amat baik. Soal yang diberikan pada siklus II memiliki indikator yang sama dengan soal tes hasil belajar siklus I. Jumlah soal per indikator sama banyak dengan siklus I. Adapun hasil belajar pada siklus II sesuai dengan tabel sebanyak 35 siswa $(97,201 \%)$ berhasil mencapai ketuntasan dengan nilai $>65$. Namun sebanyak 3 orang siswa $(7,69 \%)$ tetap belum mencapai ketuntasan dengan kriteria cukup. Tingkat penguasaan siswa tiap indikator pada siklus I dan II disajikan dalam Gambar 1, sedangkan 
distribusi kualifikasi tingkat pemahaman siswa setelah siklus II dapat dilihat pada Tabel 2.

Tabel 2. Distribusi tingkat pemahaman siswa setelah siklus II

\begin{tabular}{lccc}
\hline Rentang nilai & Kualifikasi & $\begin{array}{c}\text { Jumlah } \\
\text { siswa }\end{array}$ & $\begin{array}{c}\% \\
\text { siswa }\end{array}$ \\
\hline$\geq 95 \%$ & Istimewa & 0 & 0 \\
\hline $80 \%-94,9 \%$ & Amat Baik & 17 & 44,7 \\
\hline $65 \%-79,9 \%$ & Baik & 18 & 44,7 \\
\hline $55 \%-64,9 \%$ & Cukup & 3 & 7,9 \\
\hline $40,1 \%-54,9 \%$ & Kurang & 0 & 0 \\
\hline$\leq 40 \%$ & $\begin{array}{c}\text { Amat } \\
\text { Kurang }\end{array}$ & 0 & 0 \\
\hline
\end{tabular}

Hasil analisis tindakan pada siklus II menunjukkan bahwa terjadi peningkatan pemahaman dan minat siswa yang positif terhadap model siswa pada materi penyetaraan persamaan reaksi kimia sederhana. untuk mencapai ketuntasan belajar siswa kelas $\mathrm{X}-\mathrm{D}$ MAN 3 Banjarmasin.

Tingkat pemahaman siswa diduga masih dapat ditingkatkan melalui penambahan siklus dan peningkatan proses pembelajaran. Media yang digunakan dalam penelitian ini bersifat tertutup yakni disertai narasi dan penjelasan. Oleh karena itu peranan guru dalam menjelaskan dan menekankan konsep selama pembelajaran sangat penting untuk menunjang keberhasilan penggunaan media ini. Pada penelitian ini siswa diberikan kopi materi tayangan, agar lebih berkonsentrasi pada pemahaman konsep.

\section{PENUTUP}

Penggunaan metode telunjuk kanan dan telunjuk kiri dapat meningkatkan pemahaman siswa terhadap materi pelajaran pada pokok bahasan penyetaraan persamaan reaksi sederhana. Ketuntasan belajar pada siklus I adalah 70,75 \% menjadi 97,20\% pada siklus II.
Adanya respon positif siswa kelas $\mathrm{X}-\mathrm{D}$ MAN 3 Banjarmasin pada pembelajaran pada pokok bahasan penyetaraan reaksi sederhana ditunjukan dengan peningkatan keterampilan kooperatif terutama kemampuan siswa untuk melakukan hubungan sosial seperti mau bertanya pada orang lain, menghargai pendapat orang lain, mau menerima saran orang lain dan mau menyumbangkan ilmu, yang sebelum tindakan kurang mampu dan setelah dilakukan tindakan menjadi sangat mampu.

Dari hasil penelitian, pembahasan dan kesimpulan yang telah diuraikan dapat dikemukakan beberapa saran yaitu :

1. Hendaknya para guru kimia dapat menyusun program pengajaran kimia dan pembelajaran kimia yang aktif, kreatif, efektif, dan menyenangkan.

2. Diharapkan kepada guru bidang kimia untuk menjadikan metode telunjuk kanan dan telunjuk kiri sebagai pengajaran alternatif dalam upaya meningkatkan pemahaman siswa dalam pembelajaran.

\section{DAFTAR PUSTAKA}

Arifin, Mulyati. (1994). Pengembangan Program Pengajaran Bidang Studi Kimia. Bandung: Airlangga Press.

Arikunto, S. (1997). Dasar-Dasar Evaluasi Pendidikan. Jakarta: Bina Aksara

Depdikbud. (1995). Kurikulum Kimia 1994 Sekolah Menengah Umum $(G B P P)$. Jakarta : Kanwil Depdikbud

Karyadi, B. (1995). Kimia 2 Untuk SMU Kelas 2. Jakarta: Depdikbud Balai Pustaka.

Marganof. (1998). "Kesulitan - kesulitan yang dialami siswa kelas II SMUN1 Kotto XI Tarusan Dalam 


\begin{abstract}
Memahami Materi Persamaan
Reaksi dan Upaya

Memperbaikinya Dengan

Menerapkan Metode Pemecahan

Masalah". Tesis. Tidak

Diterbitkan : PPS IKIP, Malang.
\end{abstract}

Nurhadi Th., dan Sri Anitah W. (1999).

Strategi Belajar Mengajar.

Jakarta : Universitas Terbuka.

Slameto. (1995). Belajar dan Faktorfaktor yang Mempengaruhinya. Jakarta : Rineka Cipta.

Subagyo, J.K. (1997). Metode Penelitian Dalam Teori dan Praktek. Jakarta : Rineka Cipta.

Sudjana, N dan Ibrahim. (1989).

Penelitian dan Penilaian

Pendidikan. Bandung : Sinar Baru

Sund, R.B dan Trowbridge, L.W. (1973). Teaching Science by Inquiry in The Secondary Schools. Ohio: Charles E. Merryl Publishing Company.

Sutresna, N. (1994). Penuntun Belajar Kimia I Untuk SMU Kelas I. Bandung : Ganeca Exact.

Tresna Sastrawijaya. (1988). Proses Belajar Mengajar Kimia. Jakarta : P2LPTK Dirjen Dikti Departemen Pendidikan Dan Kebudayaan RI.

Warkitri, Anitah, S.W, Chasiyah dan Legowo, E. (1990). Penilaian Pencapaian Hasil Belajar. Jakarta : Karunika.

Winarti, W, Sajimanto. (1995). Kimia SMU Kelas 2. Jakarta : Pabelan 